\title{
Motor neurone disease and hyperthyroid Graves' disease: a chance association?
}

\author{
JOHN MCMENAMIN, AND MICHAEL CROXSON \\ From the Department of Endocrinology Auckland Hospital, Auckland, New Zealand
}

SUMMARY The presentation of a 56-year-old woman with coexisting hyperthyroid Graves' disease and motor neurone disease is described. Circulating immune complexes were detected in the serum of seven patients with motor neurone disease (five cases) or primary lateral sclerosis (two cases), including a man with insulin-dependent diabetes mellitus.

An unusual link between autoimmune adrenal insufficiency and a myeloneuropathy has recently been suggested by Griffin et al. ${ }^{1}$ There is, however, no known relationship between motor neurone disease and autoimmune endocrine disease. The presentation of a woman with hyperthyroid Graves' disease and motor neurone disease led us to consider whether this was simply a chance association. The case reports of another woman with hyperthyroid Graves' disease and primary lateral sclerosis, and of a man with longstanding diabetes mellitus complicated by motor neurone disease are described. Detailed analysis of thyroid function in six other patients with motor neurone disease or primary lateral sclerosis revealed no unsuspected cases of autoimmune thyroid disease. Circulating immune complexes were present in the serum of seven patients including two classified as have primary lateral sclerosis.

\section{Case reports}

A clinical summary of the patients included in this study together with thyroid function tests and measurement of immune complexes is shown in the table. Patients considered for study were those classified by a neurologist as having motor neurone disease according to section 348.0 of the ICS system of disease indexing. A final clinical diagnosis of motor neurone disease was accepted

Address for correspondence and reprint requests: Dr Michael Croxson, Department of Endocrinology, Auckland Hospital, Park Road, Auckland, New Zealand.

Accepted 7 June 1979 in the presence of progressive combined upper and lower motor neurone signs; in particular, muscle wasting and fasciculations were present and electromyography confirmed the presence of muscle denervation. Patients classified in the table as having primary lateral sclerosis (cases 2 , 4 , and 5) have slowly progressive disease confined to corticospinal tracts and normal myelography. They do not, therefore, fulfill generally accepted criteria for the diagnosis of motor neurone disease.

CASE 1

A 54 year old Caucasian woman was admitted to hospital for neurological investigation. Six months before admission she had developed spasms in the left hand and noted residual weakness in her left arm and leg which tended to drag on walking. Brief spasms of the left hand had continued and the left-sided weakness failed to improve. Examination revealed left-sided pyramidal tract type weakness of the arm and leg but no muscle wasting or fasciculation. Tendon reflexes were brisk but not pathological or asymmetrical. Investigation of this apparent left hemiparesis included normal pattern visual evoked potentials and normal right carotid angiogram. In addition she gave a history of mild breathlessness, palpitations, and nervousness for six months. Signs of bilateral lid retraction, a fine tremor, and a resting heart rate of 100 per minute together with minor diffuse thyroid gland enlargement suggested thyrotoxicosis. The diagnosis was confirmed by conventional thyroid function tests (table), thyroidal uptake of ${ }^{99} \mathrm{M}$ - 
Table Clinical summary and results of thyroid function tests

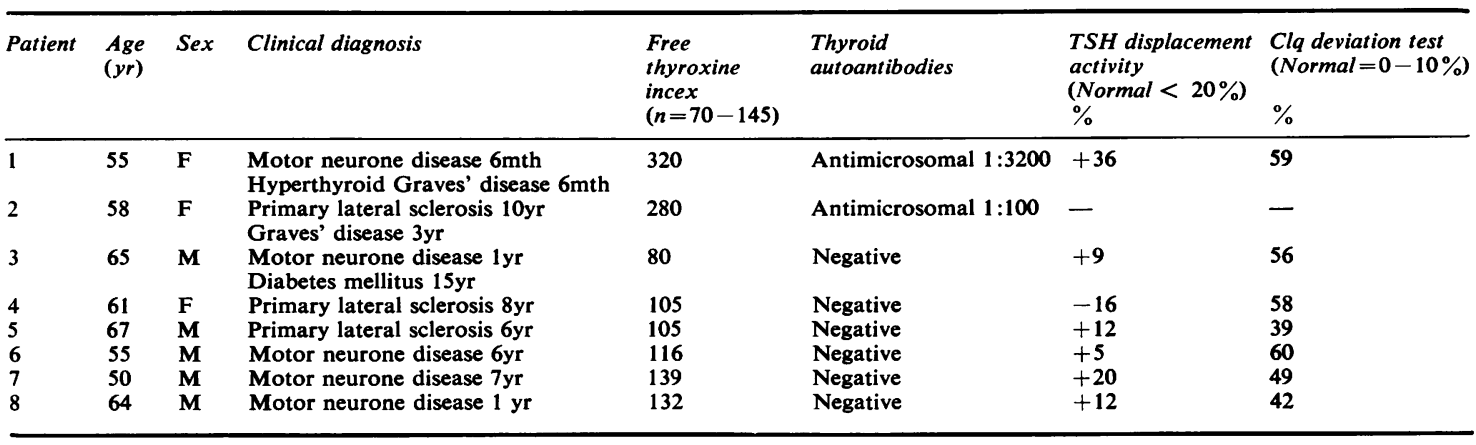

technetium pertechnetate was elevated, and a scan of the gland confirmed the presence of diffuse hyperplasia. Tests for thyroid autoantibodies and thyroid stimulating immunoglobins (thyroid stimulating hormone displacement activity) were also positive. Treatment with antithyroid drugs was initiated and three months later she received therapeutic radioiodine, later requiring thyroxine replacement therapy. Despite effective antithyroid therapy, three months after presentation she complained of increasing muscular weakness and cramps which were now present in both limbs and associated with wasting and fasciculation of the small muscles of her left hand and also of her tongue. Electromyography now showed high amplitude polyphasic potentials of denervation in biceps, tibial and dorsal interosseous muscles. She has continued to have progressive involvement of bulbar muscles with difficulty in swallowing and speaking one year after her initial symptoms.

Further serological studies three months after radioiodine ablation of the thyroid gland showed the presence of microsomal antibodies, now in high titre of 1 in 25600 and TDA remained positive at $+33 \%$. Serum antinuclear factor was negative, parietal cell antibodies by immunofluorescence were positive. Total serum complement and anticomplementary activity were normal, and serum DNA concentration was undetectable.

\section{CASE 2}

A 50 year old Caucasian woman presented in 1970 with a three year history of unsteadiness in walking. Examination revealed generalised spasticity, particularly in the legs, associated with pathologically brisk reflexes including a brisk jaw jerk and extensor plantar responses. A lumbar pneumoencephalogram indicated mild general- ised brain atrophy although there was no associated impairment of intellectual function. A diagnosis of a primary motor disorder, possibly primary lateral sclerosis was made. In 1975 she presented with a four month history of tremor and increased difficulty in walking. The development of heat intolerance, $12.7 \mathrm{~kg}$ weight loss, and palpitations as well as diarrhoea were now present. She had diffuse thyroid enlargement, mild proptosis and lid retraction, and thyroid function tests confirmed the presence of hyperthyroid Graves' disease. Neurological signs were unchanged, although proximal weakness had increased in both arms and legs. An EMG showed minor changes of neurogenic atrophy in the vastus lateralis muscle with broad polyphasic units. Treatment with antithyroid medication and then therapeutic radioiodine resulted in some improvement in muscle power but over the next three years leg weakness and spasticity has been slowly progressive, necessitating the use of a wheelchair.

\section{CASE 3}

A lean 65 year old Caucasian man developed diabetes mellitus when aged 50 years, becoming insulin-dependent from the age of 58 years. One brother also had insulin-dependent diabetes mellitus from age 40 years, and a sister died of juvenile diabetes aged 13 years. There was no other family history of endocrine or neurological disease among his parents and two normal sisters, and no past history of thyroid or neurological disease. His diabetic control was good, and there was no evidence of renal or retinal complications or overt peripheral neuropathy. Shortly before retirement at the age of 65 years he began to develop dysarthria and difficulty in swallowing with marked progression over one year. Examination one year after the onset of symptoms 
revealed signs of a severe bulbar and pseudobulbar palsy with spastic speech, brisk jaw and palmo-mental reflexes, and wasting and fasciculation of the tongue. Minimal wasting and fasciculations were present in both upper arms. An EMG demonstrated neurogenic changes with polyphasic motor unit potentials up to $4 \mathrm{mV}$ in three limbs. There was in addition, a slight sensory neuropathy in the median nerve, consistent with longstanding diabetes. Other serological tests showed normal total serum complement and anticomplementary activity, and serum DNA concentration was undetectable. Measurement of islet cell antibodies by immunofluorescence was negative.

\section{Methods}

Conventional methods were used for the measurement of serum thyroxine by competitive protein binding and of the resin T3 uptake, with derivation of a Free Thyroxine Index. Thyroid microsomal autoantibodies were measured by haemagglutination. Thyrotrophin displacement activity (TDA), a measure of thyroid stimulating immunoglobins, is derived from the competitive displacement of labelled thyrotrophin (TSH) in a receptor assay using the method of Smith and Hall. $^{2}$ In this laboratory $84 \%$ of patients with untreated hyperthyroid Graves' disease have a significant TDA of greater than $20 \%$ when compared with 75 normal subjects or patients without thyroid disease. The $\mathrm{Clq}$ deviation test for measurement of immune complexes in serum was performed according to the method of Sobel et $a l^{3}$ and serum DNA by the method of Giles and Myers. ${ }^{4}$

\section{Results}

Analyses of six patients (cases 3 to 8 in table) revealed no evidence of unsuspected hyperthyroidism or autoimmune thyroid disease. The $\mathrm{Clq}$ deviation test was positive in the serum of all seven patients measured. Although this test is not specific for the presence of immune complexes and may show interference by serum DNA or endotoxins, DNA was undetectable in the serum of cases 1 and 3 .

\section{Discussion}

The simultaneous presentation of a 56 year old woman with hyperthyroidism and motor neurone disease is, for several reasons, probably due to chance alone. Firstly the incidence of motor neurone disease in New Zealand is similar to that of other non-endemic areas. In the eight years from 1968 to 1975 , the crude death rate from motor neurone disease was $1 \cdot 19 / 100000$ adjusted to the 1974 Caucasian population of 2.79 million with a male/female ratio of 1.52 . Assuming a female prevalence of approximately $2 / 100000$ for motor neurone disease and 20/ 100000 for hyperthyroid Graves' disease, ${ }^{5}$ a likely association of these two conditions by chance is about 1 in 2.5 million without any adjustment for age. This could result every five to 10 years in the base hospital drawing area of approximately half a million women.

Secondly, patients with motor neurone disease are usually fully investigated for any remediable cause which may explicitly include thyroid function tests. ${ }^{6}$ A review of the literature reveals only one report of any such similar association. Mager $^{7}$ describes two patients with hyperthyroidism and benign amyotrophic lateral sclerosis. The first patient was a man with an unusually slow progression of his neurological illness which began at the age of 23 years and continued for 20 years. Hyperthyroidism developed 15 years after the onset of his neurological illness. The second description was of a woman who developed Graves' disease at the age of 18 years with the development of amyotrophic lateral sclerosis two years after effective antithyroid therapy with radioiodine. There was minimal progression of the neurological disease over a total nine year follow-up period. The history of these patients is quite unlike the inexorable progression of the disease affecting cases 1 and 3 in the present study.

A proximal myopathy which rarely involves bulbar muscles may complicate the clinical course of patients with thyrotoxicosis. ${ }^{8}$ Similarly, thyrotoxic patients have been described with corticospinal tract symptoms and signs which usually resolve on return to the euthyroid state. ${ }^{9}$

The nature of motor neurone disease and the detection of circulating immune complexes in all patients of the present study, however, warrant speculation on a possible immunological association. Hyperthyroid Graves' disease is probably caused by the presence in serum of specific thyroid stimulating immunoglobulins. ${ }^{10}$ Circulating immune complexes have also been detected in patients with Graves' disease ${ }^{11}$ and diabetes mellitus ${ }^{12}$ as well as in many other diseases of diverse aetiology. Their detection may be significant as a pointer to a possible causative antigen. Although distinctive haplotypes of tissue antigen typing have been described 
both for patients with Graves' disease and with amyotrophic lateral sclerosis, ${ }^{13}$ these give no evidence for an overlapping genetic predisposition. On the other hand Hoffman et al $^{14}$ have recently described diminished cellular immunity and an increased frequency of HLA-Bw35 haplotype in Guamanian patients with amyotrophic lateral sclerosis. This histocompatability antigen is also increased in Japanese patients with Hashimoto's thyroiditis. ${ }^{15}$

The presence and significance of circulating immune complexes in the serum of patients with motor neurone disease has recently been noted and discussed by Oldstone et al. ${ }^{16}$ Their studies have so far failed to reveal any specific viral or myelin antigens in tissues subject to deposition of these immune complexes. The production of antibodies and the formation of immune complexes may be a secondary response to damaged neural tissue rather than a primary response to a causative agent such as a virus or a central nervous system specific protein. Increasing resolution of these CNS proteins ${ }^{17}$ combined with the development and application of human specific antiserum ${ }^{18}$ remains a promising line for future immunological research. An initial approach might include indirect immunofluorescence using serum from patients with motor neurone disease layered on normal and diseased spinal cord sections.

We acknowledge gratefully the help of $\mathrm{Mr}$ Philip Wrightson for his German translation, of Dr Ian Simpson for the measurement of immune complexes, and of the neurologists of Auckland Hospital for permission to study their patients.

\section{References}

1 Griffin JW, Goren E, Schaumburg H, Engel WK, Loriaux L. Adrenomyeloneuropathy: a probable variant of adrenoleukodystrophy. Clinical and endocrinologic aspects. Neurology (Minneap) 1977; 27:1107-13.

2 Smith BR, Hall R. Binding of thyroid stimulators to thyroid membranes. FEBS Lett 1974; 42:301-4.

3 Sobel AT, Bokisch VA, Müller-Eberhard HJ. Clq deviation test for the detection of immune complexes, aggregates of IgG and bacterial products in human serum. J Exp Med 1975; 142:139-50.

4 Giles KW, Myers A. An improved diphenyl- amine method for the estimation of deoxyribonucleic acid. Nature 1965; 206:93.

5 Tunbridge WMG, Evered DC, Hall R et al. The spectrum of thyroid disease in a community: the Wickham Survey. Clin Endocrinol 1977; 7: 481-94.

6 Utterback RA, Cummins AJ, Cape CA, Goldenberg J. Pancreatic function in amyotrophic lateral sclerosis. J Neurol Neurosurg Psychiatry 1970; 33:544-7.

7 Mager J. Myatrophe Lateralsklerose: Zwei ungewöhnliche Verläufe. Der Nervenartz 1976; 47:261-4.

8 Kammer GM, Hamilton CR. Acute bulbar muscle dysfunction and hyperthyroidism: A study of four cases and review of the literature. Am J Med 1974; 56:464-70.

9 Garcia CA, Fleming H. Reversible corticospinal tract disease due to hyperthyroidism. Arch Neurol 1977; 34:647-8.

10 O'Donnell J, Trokoudes K, Silverberg J, Row V, Volpé R. Thyrotrophin displacement activity of serum immunoglobins from patients with Graves' disease. J Clin Endocrinol Metab 1978; 46:770-2.

11 Calder EA, Penhale WJ, Barnes EW, Irvine WJ. Evidence for circulating immune complexes in thyroid disease. $\mathrm{Br}$ Med J 1974; 1:30-1.

12 Irvine WJ, Al-Khatees SF, Di Mario U et al. Soluble immune complexes in the sera of newly diagnosed insulin-dependent diabetics and in treated diabetics. Clin Exp Immunol 1977; 30: 16-21.

13 Terasaki PI, Mickey MR. HL-A haplotypes of 32 diseases. Transplant Rev 1975; 22:105-19.

14 Hoffman PM, Robbins DS, Nolte MT, Gibbs CJ, Gajdusek DC. Cellular immunity in Guamanians with amyotrophic lateral sclerosis and Parkinsonism-dementia. N Engl J Med 1978; 299:680-5.

15 Moens H, Farid NR. Hashimoto's thyroiditis is associated with HLA-DRw3. N Engl J Med 1978; 299:133-5.

16 Oldstone MBA, Wilson CR, Perrin LH, Norris FH. Evidence for immune-complex formation in patients with amyotrophic lateral sclerosis. Lancet 1976; 2:169-72.

17 Block E. Nervous system specific proteins. J Neurochem 1978; 30:7-14.

18 Whittingham S, Benuna B, Carnegie PR, McPherson TA. Properties of antibodies produced in rabbits to human myelin and myelin basic protein. Int Arch Allergy Appl Immunol 1972; 42:250-63. 